\title{
Covid-19: Allow pharmacists to dispense controlled drugs without prescription, urge specialists
}

\author{
Gareth lacobucci
}

The BMJ

Revised legislation allowing pharmacists to supply some controlled drugs without prescription must be enacted "without delay" to protect patients and to support clinicians, experts have said.

Last week (28 April) the UK home secretary, Priti Patel, laid legislation before parliament that allows for a relaxation of the regulations for prescribing controlled drugs, to ensure access is not delayed during the covid-19 pandemic. ${ }^{1}$ The relaxation would allow pharmacists, in a pandemic situation, to supply some drugs that were previously only supplied to a patient by doctors on prescription. It would also allow pharmacists, in cases of shortages, to alter dosages or substitute drugs without having to go back to the prescribing doctor to seek a new prescription.

But the changes can be triggered only with the express permission of the home secretary, who has so far not given this despite the legislation being tabled to be used in situations of crisis.

In a letter to the home secretary sent on 4 May more than 50 experts from across the health sector warned that further delay could put patients at risk, including people with covid-19 who may be experiencing delays in accessing vital drugs such as morphine.

They wrote, "Given the urgency with which prescribers and pharmacists need to provide pain control and reduce severe breathing difficulty for patients with covid-19 this legislation needs to be enacted urgently.

"We call on the home secretary to trigger the useful actions contained in the legislation without delay as this will benefit health care staff and most importantly patients."
Ian Hamilton, an academic at the University of York with an interest in addiction and mental health, who coordinated the letter, told The BMJ that although it was positive that the home secretary laid the legislation before parliament, it needed to be activated now.

He said, "The home secretary is saying that she will trigger it if she perceives that to be a crisis. And our view is the crisis is now. How much worse does it have to get before it crosses this threshold, whatever that threshold is?"

"Each day there's a delay our concern is that the potential for suffering just goes on."

Hamilton explained that the amended rules would help prescribing doctors in primary and secondary care, nurses, pharmacists, and most importantly patients.

He said, "From an acute point of view, whether it's in the community or in the hospital setting, it [the legislation] just speeds up the whole process of getting pain relief or, critically, alleviation of shortness of breath or severe breathlessness sorted in a timely way.

"The problem with this is that if somebody is in a lot of pain and they're really severely short of breath, that in itself is problematic because it can trigger a cardiac arrest. A worst case scenario is that someone could actually die because of a two or three hour delay in getting morphine. So this is something that I think is essential for healthcare workers to have.'

1 The Misuse of Drugs (Coronavirus) (Amendments Relating to the Supply of Controlled Drugs During a Pandemic etc.) Regulations 2020. www.legislation.gov.uk/uksi/2020/468/ made.

Published by the BMJ Publishing Group Limited. For permission to use (where not already granted under a licence) please go to http://group.bmj.com/group/rights-licensing/ permissions 